\title{
Recidiva da Tuberculose: fatores associados em um Grupo de Vigilância Epidemiológica de São Paulo
}

Isabela Cristina Rodrigues ${ }^{1}$, Silvia Helena Figueiredo Vendramini ${ }^{2}$, Maria Amélia Zanon Ponce ${ }^{3}$, Antônio Ruffino-Neto ${ }^{4}$, Nilza Gomes de Souza ${ }^{5}$, Francisco Chiaravalloti Neto ${ }^{6}$, Maria de Lourdes Sperli Geraldes Santos ${ }^{7}$, Anneliese Domingues Wysocki ${ }^{8}$

${ }^{1}$ Enfermeira, Mestre em Enfermagem. Enfermeira do Grupo de Vigilância Epidemiológica do Estado de São Paulo. São Paulo, SP, Brasil. E-mail:

isabela_famerp@yahoo.com.br.

${ }^{2}$ Enfermeira, Doutora em Enfermagem em Saúde Pública. Professora Adjunto da Faculdade de Medicina de São José do Rio Preto. São José do Rio Preto, SP, Brasil. E-mail:

silviahve@gmail.com.

${ }^{3}$ Enfermeira, Doutora em Enfermagem em Saúde Pública. Gerente em DST/Aids do Secretaria de Saúde de São José do Rio Preto. São José do Rio Preto, SP, Brasil. E-mail:

amelinha_famerp@yahoo.com.br.

${ }^{4}$ Médico. Doutor em Saúde na Comunidade. Professor Titular da Faculdade de Medicina de Ribeirão Preto da Universidade de São Paulo. Ribeirão Preto, SP, Brasil. E-mail: aruffino@fmrp.usp.br.

${ }^{5}$ Enfermeira, Mestre em Ciências. Enfermeira da Secretaria de Estado da Saúde de São Paulo. Neves Paulista, SP, Brasil. E-mail: gve29tbmonitor@saude.sp.gov.br.

${ }^{6}$ Engenheiro civil, Doutor em Saúde Pública. Professor Associado da Faculdade de Saúde Pública da Universidade de São Paulo. São Paulo, SP, Brasil. E-mail: franciscochiar@usp.br.

${ }^{7}$ Enfermeira, Doutora em Enfermagem. Professora Adjunto da Faculdade de Medicina de São José do Rio Preto. São José do Rio Preto, SP, Brasil. E-mail: mlsperli@gmail.com.

${ }^{8}$ Enfermeira, Doutora em Ciências da Saúde. Professora Efetiva da Universidade Federal de Mato Grosso do Sul. Três Lagoas, MS, Brasil. Email: lilisew@yahoo.com.br.

Recebido: 18/08/2016.

Aceito: 08/12/2016.

Publicado: 03/05/2017.

Como citar esse artigo:

Rodrigues IC, Vendramini SHF, Ponce MAZ, Ruffino-Neto A, Souza NG, Chiavavalloti Neto F, et al. Recidiva da Tuberculose: fatores associados em um Grupo de Vigilância Epidemiológica de São Paulo. Rev. Eletr. Enf. [Internet]. 2017 [acesso em:____];19:a06. Disponível em: http://dx.doi.org/10.5216/ree.v19.42694.

\section{RESUMO}

Analisar os fatores associados aos casos de recidiva de tuberculose (TB) em notificações no Grupo de Vigilância Epidemiológica XXIX/São José do Rio Preto/SP. Trata-se de um estudo caso-controle, analisando as notificações de TB pulmonar no período de 1996 a 2014. Considerou-se caso notificações de "Recidiva" e controle: notificações classificadas como caso "Novo" e cujo desfecho foi "Cura". Utilizou-se para a análise dos dados o odds ratio e análise multivariada com intervalo de confiança de 95\%. As variáveis sexo e desfecho desfavorável no 7ํ mês permaneceram significativamente associadas à recidiva. O sexo masculino apresentou 1,8 vezes maior risco $(p=0,0551)$ e os indivíduos que obtiveram desfecho desfavorável no 70 mês de tratamento apresentaram 4,6 vezes mais chance de ter recidiva $(p=0,0000)$. Foram encontrados dois fatores associados à recidiva: o sexo masculino e o desfecho desfavorável do tratamento, o que mostra a necessidade de avaliar a qualidade da assistência prestada.

Descritores: Tuberculose; Recidiva; Terapêutica; Estudos de Casos e Controles.

\section{INTRODUÇÃO}

A Tuberculose (TB) é uma doença reconhecida mundialmente como prioritária, frente à sua magnitude. Em 2012, a Organização Mundial da Saúde (OMS), estimou 1,3 milhões de óbitos no mundo, sendo o Brasil responsável por $80 \%$ dos casos, listado entre os 22 países priorizados pela OMS, com o Estado de São Paulo sendo o maior notificador ${ }^{(1-3)}$. 
No Brasil, uma das estratégias atuais para o controle da doença é um conjunto de práticas que visam à adesão ao tratamento, reduzindo o abandono e elevando as taxas de cura, principalmente através do Tratamento Diretamente Observado (TDO), que consiste na observação pelo profissional de saúde, da tomada do medicamento pelo paciente, como forma de construção de vínculo ${ }^{(1-2)}$. A literatura comprova que nos locais onde a cobertura da estratégia TDO é efetiva, as taxas de cura podem atingir cerca de $87 \%^{(4)}$.

Entretanto, existem obstáculos para a cura da doença, prolongando o período de transmissibilidade e causando impacto social, frente ao custo econômico e aparecimento de multirresistência. Os principais complicadores são os casos de retratamento, seja por recidiva da doença ou abandono ${ }^{(4)}$.

A recidiva é o aparecimento da doença, em sua forma ativa, após completar um tratamento e receber alta por cura. Pode ser causada por reativação endógena, devido a determinantes biológicos, ou reinfecção exógena, mais frequente em regiões endêmicas, sendo estas condições clinicamente iguais, possível de diferenciação apenas por técnicas moleculares, porém pouco realizada, tendo em vista o tratamento ser o mesmo em ambos os $\operatorname{casos}^{(1,4)}$

A reativação bacilar ainda é uma incógnita, havendo apenas hipóteses. Acredita-se que aproximadamente $90 \%$ dos indivíduos infectados permanecem no estado latente; cinco a $10 \%$ progridem para a doença e $5 \%$ dos indivíduos que se curaram apresentaram reativação endógena ${ }^{(1)}$.

Alguns estudos regionais, em Recife/PE e em Campinas/SP, demonstraram que em torno de $15 \%$ dos casos notificados/ano são retratamentos. Sabe-se que um esquema de tratamento da TB quando seguido de forma adequada é capaz de proporcionar taxas de cura próximas aos $100 \%$ assim como taxas de recidiva menores que $5 \%^{(5-6)}$. Pacientes que receberam a quimioterapia adequada, a chance de reativação é mais frequente nos dois primeiros anos; já o inverso, à reativação se dá poucos meses após a alta ${ }^{(3,6-8)}$.

O âmbito da não adesão ao tratamento da TB é multidimensional, envolvendo o tratamento (quantidade de medicamentos, longa duração e presença de efeitos colaterais), os serviços de saúde e o contexto sociocultural, como questões de alcoolismo e drogadição, fatores de irregularidade do tratamento que influenciam diretamente nos abandonos, óbitos e recidivas da $\mathrm{TB}^{(5-6)}$.

Dentre a linha de determinantes para o aparecimento das recidivas, acredita-se que indivíduos com imunossupressão, principalmente por HIV/Aids e Diabetes Mellitus teria o processo de destruição bacilar prejudicado, aumentando a probabilidade de estado de latência do bacilo ${ }^{(5-6)}$.

Com o advento do HIV, a literatura mostra elevadas taxas de recidiva e mortalidade em pacientes coinfectados $\mathrm{TB} / \mathrm{HIV}^{(4-5,9)}$. A mortalidade é duas vezes maior neste grupo, não apenas pelo grau de imunossupressão, mas também pela associação com outras comorbidades e o não uso de antiretroviral. Frente a este cenário que a OMS preconiza a testagem de HIV para todos os pacientes com diagnóstico de $\mathrm{TB}^{(4-5,8-9)}$

Os pacientes tabagistas também são vistos como potenciais de recidiva. A nicotina é a substância que mais se revela importante na reativação, diminuindo a resistência do hospedeiro e alterações alveolares, aumentando o risco de persistência da bactéria após o tratamento ${ }^{(4)}$. 
Nota-se que o cenário das recidivas ainda é complexo, porém pouco investigado, com inúmeras lacunas a serem esclarecidas. Apesar dos notórios resultados após a implantação do PCNT, hoje, observa-se a necessidade de aprimorar as estratégias e lapidar os olhares para índices que repercutem a qualidade assistencial.

Neste âmbito, este estudo objetivou analisar os fatores associados aos casos de recidiva de TB pulmonar entre os anos de 1996 a 2014 notificados no Grupo de Vigilância Epidemiológica XXIX/São José do Rio Preto/SP (GVE XXIX).

\section{MÉTODOS}

Estudo descritivo-analítico, tipo caso controle (1:1). Foram consideradas as notificações de TB pulmonar no período de 1996 a 2014 no Sistema de Informação de Controle de Pacientes com Tuberculose do Estado de São Paulo (TBWEB), dos municípios adscritos ao Grupo de Vigilância Epidemiológica XXIX/São José do Rio Preto/SP.

O GVE XXIX é representante regional do Centro de Vigilância Epidemiológica (CVE/SP) que normatiza o Sistema de Vigilância Epidemiológica no Estado de São Paulo. Abrange 67 municípios pertencentes aos Colegiados Regionais de Gestão de Catanduva, José Bonifácio, Votuporanga e São José do Rio Preto, representando uma das maiores regionais em extensão e número de municípios, totalizando $3 \%$ do total do número de casos novos de TB do Estado de São Paulo no ano de $2010^{(10)}$.

\section{Critérios de inclusão}

- Caso: as notificações de TB pulmonar classificadas como "Recidiva", na série histórica de 1996 a 2014.

- Controle: as notificações classificadas como caso "Novo" e cujo desfecho foi "Cura", na séria história de 1996 a 2014

Foram selecionadas duas variáveis geradoras de confundimento para o pareamento:

- Ano: ao longo dos anos o tratamento da TB se modificou (introdução de medicações, visão dos profissionais para com a doença e investimento governamental).

- Município notificante: heterogeneidades entre os municípios (sociais, demográficas, socioeconômicas) podem interferir na assistência à saúde. Os municípios foram categorizados, segundo população residente ${ }^{(11)}$ e estratificação do Instituto de Brasileiro de Geografia e Estatística $\left(\right.$ IBGE) ${ }^{(12)}$ em cinco subgrupos populacionais: zero a 4.999 habitantes, 5.000 a 9.999, 10.000 a 19.999 , 20.000 a 49.999 e maior ou igual a 50.000. Quando não possível o pareamento do mesmo município era selecionado outro que fazia fronteira e pertencia a mesma categoria populacional classificada.

\section{Critérios de exclusão}

Transferência do doente para outro Estado, mudança de diagnóstico; município não adscrito ao GVE 
29, quando não foi possível o pareamento; notificações que estavam duplicadas como "Novo" e "Recidiva", para evitar o pareamento entre notificações do mesmo doente, considerando apenas as "Recidivas"; doentes classificados com tuberculose extrapulmonar ou tuberculose mista.

No período de 1996 a 2014 foram notificados 4.429 casos de TB no Grupo de Vigilância Epidemiológica XXIX/São José do Rio Preto/SP (GVE XXIX). Após análise dos critérios de exclusão, foram selecionados neste estudo 388 registros classificados como TB pulmonar, sendo 194 considerados "casos" e 194 "controles" (Figura 1). 


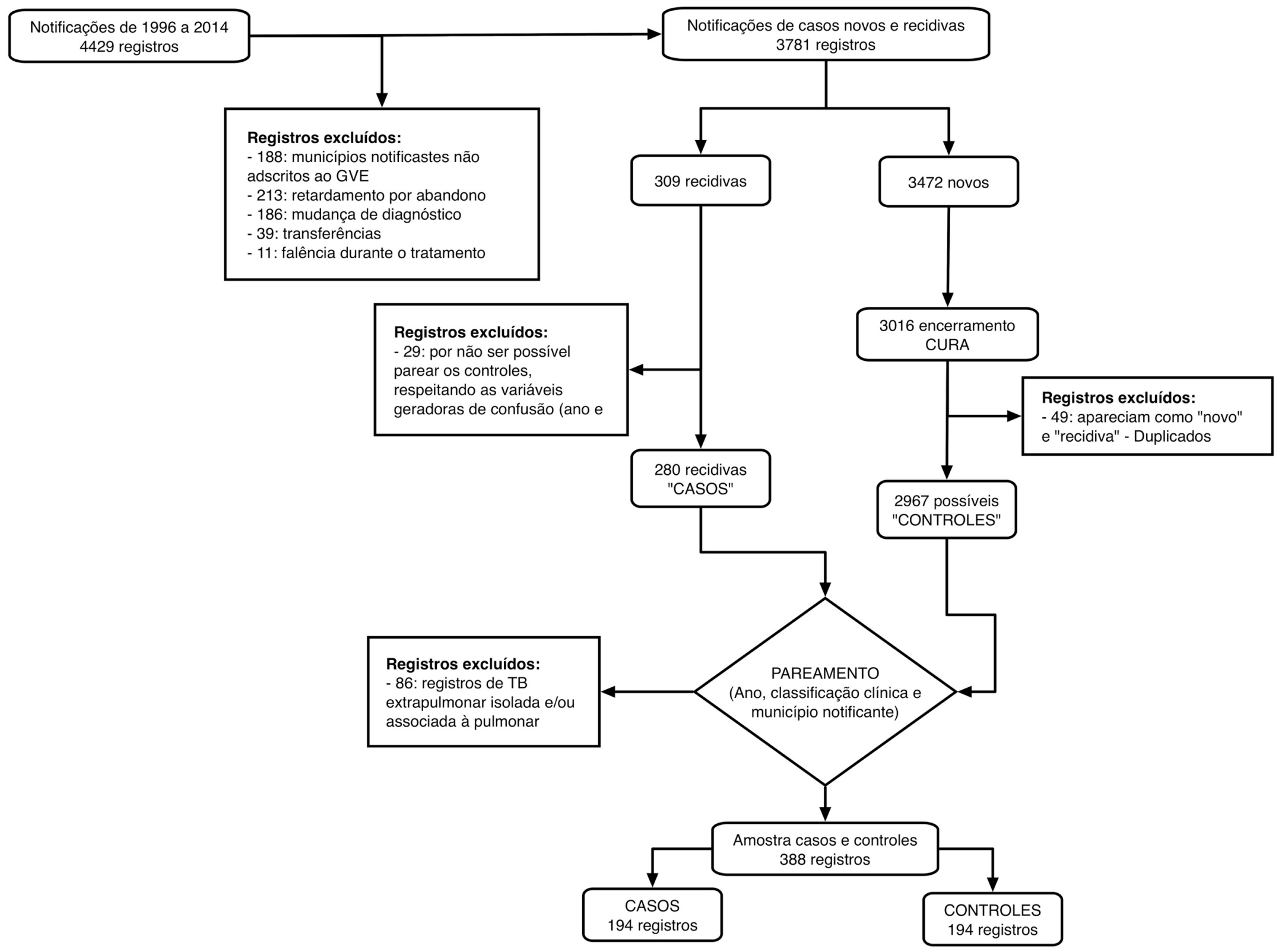

Figura 1: Visualização esquemática da triagem exploratória do sistema de informação TBWEB, 1996 a 2014. 
Para a análise dos dados, inicialmente utilizou-se frequências simples e odds ratio (OR) brutas (calculadas pela razão entre os pares discordantes), com intervalo de confiança de $95 \%$, considerando como categoria de base a categoria da variável cuja hipótese é ser de menor risco para a recidiva segundo referencial teórico. Posteriormente foi realizada análise múltipla mediante modelo de regressão logística condicional stepwise backward, considerando-se o pareamento adotado (ano e município notificante) e obtendo-se os OR ajustados. Foram consideradas inicialmente no modelo aquelas variáveis independentes que mostraram associação estaticamente significativa com o desfecho na análise bivariada no nível de $20 \%$ $(p<0,2)$. Na análise múltipla foi adotado nível de significância de 5\%. A análise dos dados foi realizada no pacote survival do Programa R versão 3.0.2. 
Quadro 1: Variáveis selecionadas para o estudo.

\begin{tabular}{|c|c|}
\hline Variáveis & Categorias/Observações \\
\hline \multirow{2}{*}{ Sexo } & Feminino \\
\hline & Masculino \\
\hline \multirow{4}{*}{ Agrupamento etário } & Crianças: de 0 a 12 anos de idade \\
\hline & Adolescente: de 13 a 18 anos de idade \\
\hline & Adulto: por não haver uma classificação oficial, foram considerados de 19 a 59 anos de idade. \\
\hline & Idoso: 60 anos ou mais de idade. \\
\hline \multirow[t]{2}{*}{ Institucionalização } & $\begin{array}{c}\text { Sim: albergues, hospitais psiquiátricos, instituições de longa permanência, institutos penais, entre } \\
\text { outros. }\end{array}$ \\
\hline & Não \\
\hline \multirow{2}{*}{$\begin{array}{l}\text { Critério de } \\
\text { confirmação } \\
\text { diagnóstico }\end{array}$} & $\begin{array}{l}\text { Clínico-epidemiológico: sem confirmação bacteriológica, ou seja, não foram realizados exames } \\
\text { bacteriológicos como baciloscopia ou cultura de escarro ou de outros materiais e/ou os exames } \\
\text { realizados tiveram resultados negativos para a doença. }\end{array}$ \\
\hline & $\begin{array}{c}\text { Bacteriológico: com confirmação bacteriológica, ou seja, foram realizados exames bacteriológicos como } \\
\text { baciloscopia e cultura de escarro ou de outros materiais e os exames tiveram resultados positivos para a } \\
\text { doença. }\end{array}$ \\
\hline \multirow{3}{*}{$\begin{array}{l}\text { Exames } \\
\text { complementares }\end{array}$} & $\begin{array}{l}\text { Sugestivo: quando foram realizados outros exames como Raio } \mathrm{X} \text {, histopatológico, necropsia entre } \\
\text { outros e tiveram resultados sugestivos para a doença. }\end{array}$ \\
\hline & $\begin{array}{l}\text { Não sugestivo: quando foram realizados outros exames como Raio X, histopatológico, necropsia entre } \\
\text { outros e tiveram resultados não sugestivos para a doença. }\end{array}$ \\
\hline & $\begin{array}{l}\text { Desconhecido: quando não havia informações sobre a realização de outros exames ou falta de } \\
\text { informações sobre resultados dos exames realizados. }\end{array}$ \\
\hline \multirow{2}{*}{ Coinfecção TB/HIV } & $\begin{array}{c}\text { Positivo } \\
\end{array}$ \\
\hline & Negativo / Desconhecido \\
\hline \multirow{2}{*}{ Coinfecção TB/Aids } & $\operatorname{Sim}$ \\
\hline & Não \\
\hline \multirow{2}{*}{ Dependência Química } & Sim \\
\hline & Não \\
\hline \multirow{2}{*}{ Diabetes Mellitus } & $\operatorname{Sim}$ \\
\hline & Não \\
\hline $\begin{array}{l}\text { Outros problemas } \\
\text { associados }\end{array}$ & $\begin{array}{l}\text { Problemas Mentais e outros. No sistema de informação utilizado, tem o item “Outros", e um campo } \\
\text { aberto para digitar a especificação. Neste estudo foram encontrados: Hipertensão Arterial, Câncer, } \\
\text { Doença Reumática, Hepatite B e C, Hipotireoidismo, Epilepsia, Doença Renal Crônica, Enfisema } \\
\text { Pulmonar, Insuficência Cardíaca e Lúpus Eritematoso. }\end{array}$ \\
\hline \multirow{3}{*}{$\begin{array}{l}\text { Desfecho favorável no } \\
\qquad 7^{\circ} \text { mês }\end{array}$} & Sim: Cura \\
\hline & Não: Óbito, Abandono / Faltoso, Em tratamento ambulatorial / Internação. \\
\hline & $\begin{array}{l}\text { O desfecho de tratamento desfavorável não inclui a recidiva, já que ter recidiva é critério de escolha } \\
\text { para ser um "Caso" dentro do estudo. }\end{array}$ \\
\hline \multirow{2}{*}{$\begin{array}{l}\text { Baciloscopia de } \\
\text { acompanhamento }\end{array}$} & $\begin{array}{l}\text { Sim: quando foi realizado pelo menos um exame de baciloscopia de escarro ou de outro material } \\
\text { durante o tratamento. }\end{array}$ \\
\hline & $\begin{array}{l}\text { Não: quando não foi realizado nenhum exame de baciloscopia de escarro ou de outro material durante } \\
\text { o tratamento. }\end{array}$ \\
\hline \multirow{2}{*}{$\begin{array}{c}\text { Internações durante o } \\
\text { tratamento }\end{array}$} & $\operatorname{Sim}$ \\
\hline & Não \\
\hline
\end{tabular}

O projeto teve aprovação do Comitê de Ética em Pesquisa da Faculdade de Medicina de São José do Rio Preto, Protocolo n ${ }^{\circ} 73763 / 2012$.

\section{RESULTADOS}

A prevalência da recidiva em relação ao total de casos no presente estudo ficou em torno de $6 \%$ (incluir no método o cálculo para a prevalência). As OR brutas mostraram que as variáveis sexo, agrupamento etário, 
problemas associados, coinfecção TB/HIV, dependência química, outros problemas associados, desfecho favorável ao $7^{\circ}$ mês e internações durante o tratamento, apresentaram associação estatisticamente significante com o desfecho (recidiva da tuberculose pulmonar) na análise bivariada

Após o ajuste do modelo na análise múltipla, apenas as variáveis sexo e desfecho desfavorável no 70 mês permaneceram significativamente associada à recidiva. 0 sexo masculino apresentou odds 1,8 vezes superior a do sexo feminino para ocorrência de recidiva e foi marginalmente significante $(p=0,0551)$. Os indivíduos que obtiveram desfecho desfavorável no 70 mês de tratamento apresentaram odds 5,6 vezes maior a dos que apresentaram desfecho favorável para ocorrência de recidiva, com $p=0,0000$.

Tabela 1: Fatores associados à recidiva da tuberculose nos casos pulmonares notificados ao GVE 29 na análise bivariada,

São José do Rio Preto, SP, Brasil, de 1996 a 2014.

\begin{tabular}{|c|c|c|c|c|c|}
\hline Variáveis & Casos (n) & Controles (n) & OR BRUTA & IC (95\%) & $\mathbf{p}$ \\
\hline \multicolumn{6}{|l|}{ Sexo } \\
\hline Masculino & 158 & 140 & 1,857 & \multirow{2}{*}[1,093-3,157]{} & \multirow[t]{2}{*}{0,0222} \\
\hline Feminino & 36 & 54 & 1 & & \\
\hline \multicolumn{6}{|l|}{ Agrupamento etário } \\
\hline Criança / Adolescente & 10 & 3 & 0,3 & \multirow[t]{2}{*}[0,0826-1,09]{} & \multirow[t]{2}{*}{0,0674} \\
\hline Adulto / Idoso & 191 & 184 & 1 & & \\
\hline \multicolumn{6}{|l|}{ Institucionalização } \\
\hline Sim & 6 & 7 & 1 & \multirow[t]{2}{*}[0,3921-3,471]{} & \multirow[t]{2}{*}{0,782} \\
\hline Não & 188 & 187 & 1,167 & & \\
\hline \multicolumn{6}{|l|}{ Critério de Confirmação Diagnóstica } \\
\hline Clínico - epidemiológico & 52 & 46 & 1,188 & \multirow[t]{2}{*}[0,742-,1,9]{} & \multirow[t]{2}{*}{0,474} \\
\hline Bacteriológico & 142 & 148 & 1 & & \\
\hline \multicolumn{6}{|l|}{ Exames complementares } \\
\hline Sugestivo & 152 & 154 & 0,9394 & \multirow[t]{2}{*}[0,5754-1,534]{} & \multirow[t]{2}{*}{0,803} \\
\hline Não sugestivo / Desconhecido & 42 & 40 & 1 & & \\
\hline \multicolumn{6}{|l|}{ Problemas Associados } \\
\hline Sim & 108 & 77 & 1,939 & \multirow[t]{2}{*}[1,274-2,952]{} & \multirow[t]{2}{*}{0,002} \\
\hline Não & 86 & 117 & 1 & & \\
\hline \multicolumn{6}{|l|}{ Coinfecção TB/HIV } \\
\hline Positivo & 40 & 18 & 2,467 & \multirow[t]{2}{*}[1,354-4,494]{} & \multirow[t]{2}{*}{0,032} \\
\hline Negativo / Desconhecido & 154 & 176 & 1 & & \\
\hline \multicolumn{6}{|l|}{ Dependência Química } \\
\hline Sim & 60 & 40 & 1,8 & \multirow[t]{2}{*}[1,104-2,935]{} & \multirow[t]{2}{*}{0,0185} \\
\hline Não & 134 & 154 & 1 & & \\
\hline \multicolumn{6}{|l|}{ Diabetes Mellitus } \\
\hline Sim & 12 & 13 & 0,9091 & \multirow[t]{2}{*}[0,3861-2,141]{} & 0,827 \\
\hline Não & 182 & 181 & 1 & & \\
\hline Outros problemas associados & & & & & \\
\hline Sim & 13 & 7 & 1,857 & {$[0,741-4,655]$} & 0,187 \\
\hline Não & 181 & 187 & 1 & & \\
\hline Desfecho favorável no $7^{\circ}$ mês & & & & & \\
\hline Sim & 90 & 156 & 1 & {$[3,239-10,08]$} & 0,0000 \\
\hline Não & 104 & 38 & 5,714 & & \\
\hline Baciloscopia de controle & & & & & \\
\hline Sim & 128 & 135 & 1 & {$[0,7581-2,201]$} & 0,347 \\
\hline Não & 66 & 59 & 1,292 & & \\
\hline Internação & & & & & \\
\hline Sim & 67 & 44 & 2,437 & {$[1,362-4,362]$} & 0,0027 \\
\hline Não & 127 & 150 & 1 & & \\
\hline
\end{tabular}


Tabela 2: Análise múltipla dos fatores associados à recidiva da tuberculose nos casos pulmonares notificados ao GVE 29, São José do Rio Preto, SP, Brasil, de 1996 a 2014.

\begin{tabular}{lccc}
\hline \multicolumn{1}{c}{ Variáveis } & ODDS AJUSTADO & IC (95\%) & P \\
\hline Sexo & & & 0.0551 \\
Masculino & 1.8046 & {$[0,9873-3,299]$} & \\
$\quad$ Feminino & 1 & & 0.0000 \\
Desfecho favorável no $7^{\circ}$ mês & & & \\
Não & 5.6717 & {$[3,2000-10,0520]$} & \\
Sim & 1 & & \\
\hline
\end{tabular}

\section{DISCUSSÃO}

No mundo, as recidivas da TB giram em torno de 5\% ao ano; no Brasil, o Ministério da Saúde (MS) prevê uma estimativa de $10 \%$ de retratamentos (abandonos e recidivas) ${ }^{(5)}$. O indicador de recidivas é relevante devido à sua interrelação com outras variáveis, como às relacionadas ao indivíduo (imunidade, comorbidades, idade, sociodemográfico) ou aos serviços de saúde (acessibilidade, formação dos profissionais de saúde) $)^{(13)}$.

$\mathrm{Na}$ história natural das doenças, a TB é mais prevalente em homens, influenciada por fatores relacionados à exposição aos riscos ${ }^{(4,14)}$. Não diferente, neste estudo, o fato de ser do sexo masculino ter maior risco para a recidiva (Tabela 01). Com relação ao agrupamento etário, a literatura mostra a faixa entre 20 e 50 anos como susceptível para a TB $^{(15)}$. Todavia, com o aumento da expectativa de vida, tem-se elevado as notificações da doença, na faixa etária acima de 60 anos $^{(15)}$.

A questão gênero é um fator influenciador no aparecimento de algumas doenças, assim como na assistência e acesso à saúde. Em países onde as questões culturais são predominantemente defensoras do sexo masculino, a utilização dos serviços de saúde, assim como os indicadores é prevalente entre eles. A TB é comumente diagnosticada em homens, o que pode ser um viés, tendo em vista a desigualdade de gênero comum na atenção à saúde inclusive no Brasil ${ }^{(14)}$.

No país, não há uma desigualdade no que se refere à disponibilidade dos serviços, já que o sistema único de saúde é universal, entretanto, sabe-se que o fato dos horários de funcionamento das unidades serem incompatíveis com os horários de trabalho da maioria da população masculina, gera uma barreira pela procura do serviço, agravando o quadro clínico, dificultando a adesão ao tratamento, facilitando o abandono e o reaparecimento da doença, seja pela reexposição ao patógeno ou pela reativação do bacilo.

A institucionalização, seja em regime carcerário ou não (asilos, albergues, etc), é vista como um dificultador para o controle da doença, facilitando a transmissão e o adoecimento ${ }^{(16)}$. Contrariando esta hipótese, neste estudo, o fato do paciente estar institucionalizado pôde ser considerado como fator de proteção. Entretanto, tendo em vista ser uma população específica, e após análise múltipla não apresentou confirmação estatística, esta hipótese não pode ser sustentada, sendo necessário um estudo à parte.

O Manual de Recomendações para o controle da TB $(2009)^{(1)}$ define a baciloscopia direta como método prioritário para o diagnóstico da doença. Para os casos de sintomatologia clínica sugestiva, mas com baciloscopia negativa, recomenda-se a realização da cultura, que é um método de elevada especificidade e 
sensibilidade, podendo aumentar em até 30\% a confirmação diagnóstica ${ }^{(1)}$.

O critério de confirmação ser clínico-epidemiológico com exames bacteriológicos negativos, não apresentou significância estatística, assim como, o fato de ter exames complementares com resultados não sugestivos e/ou desconhecidos, entretanto, é necessário destacar neste resultado, o fato da precariedade da busca ativa de casos em sintomáticos respiratório (pessoas com tosse há mais de 15 dias), que é um dos pilares do controle da doença, sendo preconizado como meta, examinar $1 \%$ da população anualmente ${ }^{(1)}$.

No estado de São Paulo, o indicador de busca ativa aumentou de 33,6\% em 2003 para 65,1\% em 2011. O GVE 29 também elevou suas taxas de 31\% em 2003 para 53\% em 2012 ${ }^{(11)}$. Apesar dos avanços, nota-se que não há uma priorização deste exame nos serviços de saúde, conforme recomendações nacionais. A literatura traz que a não solicitação do exame pode decorrer por falhas na operacionalização até indisponibilidade de insumos e/ou logística do exame, situações que não são reais no contexto do GVE 29, podendo então acreditar na falta de suspeita da doença durante o atendimento clínico ${ }^{(1)}$.

Um dos desafios para o controle da doença são as elevadas taxas de coinfecção TB/HIV, sabendo que, em torno de $8,9 \%$ dos indivíduos com TB no Brasil estão coinfectados com o vírus do HIV. 0 comprometimento da resposta imunológica do paciente coinfectado favorece o desenvolvimento da doença ativa em qualquer fase da infecção por HIV, (assintomática ou na Síndrome da Imunodeficiência Adquirida (Aids)), tornando a TB a principal causa de morte neste grupo, com taxas de óbito na coinfecção de $20 \%^{(1,4-5-}$ 7,9,16-17)

Frente à gravidade do quadro de coinfecção, dentre as estratégias preconizadas pelo PNCT está à realização de teste anti-HIV para os doentes de TB, ou seja, espera-se que $100 \%$ dos casos de TB sejam testados e que a terapia antiretroviral seja iniciada precocemente. Entretanto, a literatura traz uma baixa frequência na realização da sorologia e dados sugestivos de subnotificações, como preenchimento do campo "Não realizado", "Ignorado" ou "Em branco" ${ }^{(1,4,16)}$. Na região do GVE 29 as subnotificações tiveram um declínio na série histórica, reduzindo de 30,19\% no ano de 1996 para 8,55\% no ano de 2012.

Sabe-se que a dependência química é um fator predisponente para recidivas e o uso de droga ilícita um desafio para a saúde pública. O contexto em que vive o adicto é altamente propício para a TB, devido à precariedade dos locais de consumo da droga e do alto fluxo de pessoas, em sua maioria, com perfil imunológico prejudicado ${ }^{(6)}$, além da predisposição ao abandono do tratamento, ora pela dinâmica do seu contexto (falta de rotina, sintomas biológicos e somáticos desencadeados pelos efeitos das substâncias, falta de percepção da gravidade da doença), ora pelo relacionamento com as equipes de saúde, já que o atendimento destes pacientes exige persistência por parte dos profissionais ${ }^{(18)}$.

A conclusão efetiva do tratamento da TB tem uma importante influência para a não reativação da TB, como já apontado pela literatura. Dentre os fatores preditores para o desfecho não favorável ao final do tratamento (óbito e abandono), Orofino (2012) destaca questões sociais como o alcoolismo e fatores socioeconômicos, além de reações adversas ao tratamento medicamentoso e falta de compreensão e conhecimento quanto à doença ${ }^{(17)}$. 
Acrescenta-se as questões organizacionais dos serviços de saúde, pela dificuldade de acessibilidade (demora no atendimento, horários incompatíveis com os turnos no emprego, motivos geográficos) subestimando o conceito ampliado de saúde, e desmotivando o doente ${ }^{(19)}$. Neste estudo, não foram exploradas as questões relacionados ao desfecho desfavorável, porém foi notória a significância estatística desta variável como risco para as recidivas.

Outra questão relevante neste estudo é a efetividade do acompanhamento do doente em tratamento, sendo elevado o índice de não solicitação de baciloscopias de controle. Panjabi ${ }^{(18)}$ observou em seu estudo que há estreita relação entre o estado bacteriológico de escarro durante o tratamento e a recorrência da TB, se tornando mais um fator de risco para recidivas ${ }^{(18)}$. Sendo assim, também foram considerados no desfecho desfavorável ao 70 mês os pacientes que ainda estavam em tratamento ambulatorial e àqueles em internação.

O estudo de Bardout ${ }^{(4)}$ traz uma elevada taxa de positividade de baciloscopias em casos de recidiva durante o tratamento, trazendo como hipóteses a adesão inadequada à terapia, a prescrição de regime terapêutico incorreto ou inadequado, níveis sub-terapêuticos de drogas devido à má absorção ou interações, superinfeç̧ão com $M$. tuberculosis resistentes, sendo que tratamentos em condições experimentais, apresentam a recorrência da doença após um ou dois anos ${ }^{(4)}$.

Em tempos anteriores, o critério para alta do tratamento era o desaparecimento dos sintomas, aliados a negativação de um exame de baciloscopia. Hoje se atribui alta, após dois exames bacteriológicos negativos, sendo um deles no último mês de tratamento, independente dos sintomas clínicos ${ }^{(8)}$. A realização mensal do exame de escarro é preconizada pelo MS, mas quando não é possível, é indispensável a realização do exame no segundo, quarto e sexto mês de tratamento ${ }^{(1)}$.

Já é sabido que o diagnóstico precoce, assim como o acompanhamento rigoroso do tratamento, pode levar à redução de vários indicadores relacionados à TB, entre eles, o número de internações pela doença. Neste estudo, não se investigou os motivos para as internações, e existem inúmeros motivos para que isto aconteça, como por exemplo, a intolerância medicamentosa e seus efeitos colaterais, contudo sabe-se que a TB é uma das causas listadas como sensíveis à atenção ambulatorial, e elevados índices de internação sugerem possíveis deficiências na qualidade da assistência, ocasionando elevados custos financeiros, prolongamento do tempo de transmissão da doença e aumento de pessoas infectadas pelo contato com o indivíduo doente ${ }^{(15)}$.

Pode-se destacar como dificuldades neste estudo: o fato de levantar informações antes do ano de implantação do TBWEB, e por trabalhar com dados secundários espera-se que haja erros e/ou falta de registro de notificações; não foi possível trabalhar com todas as variáveis que seriam interessantes para o estudo, devido à falta de completude de preenchimento; devido à série histórica ampla e região extensa, não foi possível coletar dados de todos os municípios, sendo necessário o uso de critérios de exclusão; para melhor estudo com relação especificamente às recidivas, seria ideal ter dados referentes ao tratamento anterior do paciente, porém isso também não é possível, já que o TBWEB é de uso exclusivo do Estado de 
São Paulo e há vários pacientes que foram tratados anteriormente em municípios de outros estados, não sendo possível o acesso destes dados.

\section{CONCLUSÃO}

O presente estudo traçou o perfil das recidivas de TB no Grupo de Vigilância Epidemiológica XXIX - São José do Rio Preto/SP com o intuito de identificar os fatores relacionados. Foram identificadas duas variáveis significativamente associadas à recidiva: o sexo masculino, que tem 1,8 vezes maior risco do que o sexo feminino $(p=0,0551)$ e o desfecho desfavorável após o 70 mês de tratamento com seis vezes mais chance de ter recidiva $(p=0,0000)$.

Nota-se que mesmo com todos os esforços governamentais e assistenciais para o controle da TB, ainda há muito que ser feito. Pensando que se a busca por casos novos é insuficiente e nos casos encontrados e tratados há uma parcela que tem recidiva da TB, a proposta de controle efetivo da doença ainda está longe de acontecer.

O âmbito da recidiva ainda tem um longo caminho a ser percorrido. O presente estudo, mesmo sendo regionalizado, revela atual nós críticos que carecem de improrrogável resolução, destacando a deficiência da operacionalização do tratamento, como mostram os dados referentes aos critérios diagnósticos e desfechos do tratamento. Ademais, os problemas sociais que potencializam os desfechos negativos para o controle da doença urgem para necessidade de enfrentamento e não mais de marginalização.

A vigilância deve se atentar para os significativos casos de recidiva da doença e os possíveis fatores associados e, com responsabilidade compartilhada, GVE XXIX e municípios devem repensar a atenção que está sendo dada aos casos de TB, avaliar a qualidade do atendimento, e propor mudanças visando o controle efetivo da doença.

\section{REFERÊNCIAS}

1. Ministério da Saúde, Secretaria de Vigilância em Saúde, Departamento de Vigilância Epidemiológica. Manual de recomendações para o controle da tuberculose no Brasil [Internet]. Brasília: Ministério da Saúde, 2011 [acesso em: 26 abr. 2017]. Disponível em:

http://bvsms.saude.gov.br/bvs/publicacoes/manual_recomendacoes_controle tuberculose brasil.pdf.

2. Damasceno GS, Guaraldo L, Engstrom EM, Theme Filha MM, Souza-Santos R, Vasconcelos AG, et al. Adverse reactions to antituberculosis drugs in Manguinhos, Rio de Janeiro, Brazil. Clinics (Sao Paulo) [Internet]. 2013 [acesso em: 26 abr. 2017];68(3):329-37. Disponível em: http://dx.doi.org/10.6061/clinics/2013(03)OA08.

3. World Health Organization. Global tuberculosis report 2013 [Internet]. Geneva: World Health Organization, 2013 [acesso em: 26 abr. 2017]. Disponível em:

http://apps.who.int/iris/bitstream/10665/91355/1/9789241564656_eng.pdf.

4. Bardou MLD, Ervolino S, Martins Filho ISP, Yang HM, Passos SD. Recidiva de tuberculose na cidade de Jundiaí no período de 2006 a 2011: perfil clínico e epidemiológico. Medicina (Ribeirão Preto, Online) [Internet]. 2016 [acesso em: 26 abr. 2017];49(3):258-64. Disponível em: http://dx.doi.org/10.11606/issn.2176-7262.v49i3p258-264.

5. Picon PD, Bassanesi SL, Caramori MLA, Ferreira RLT, Jarczewski CA, Vieira PRB. Fatores de risco para a recidiva da tuberculose. J Bras Pneumol [Internet]. 2007 [acesso em: 26 abr. 2017];33(5):572-8. Disponível em:

http://dx.doi.org/10.1590/S1806-37132007000500013.

Rev. Eletr. Enf. [Internet]. 2017 [acesso em:_/_/_];19:a06. Disponível em: http://dx.doi.org/10.5216/ree.v19.42694. 
6. Oliveira HB, Moreira Filho DC. Recidivas em tuberculose e seus fatores de risco. Rev Panam Salud Pública [Internet]. 2000 [acesso em: 26 abr. 2017];7(4):232-41. Disponível em: http://dx.doi.org/10.1590/S1020-49892000000400004.

7. Costa CF, Cavalcante NJF. Evolução dos casos de coinfecção tuberculose/HIV com cultura positiva após alta do tratamento de tuberculose. BEPA - Boletim Epidemiológico Paulista [Internet]. 2010 [acesso em: 26 abr. 2017];7(73):410. Disponível em: http://ses.sp.bvs.br/lildbi/docsonline/get.php?id=4572.

8. Bang D, Andersen AB, Thomsen VO, Lillebaek T. Recurrent tuberculosis in Denmark: relapse vs. re-infection. Int J Tuberc Lung Dis [Internet]. 2010 [acesso em: 26 abr. 2017];14(4):447-53. Disponível em:

http://www.ingentaconnect.com/content/iuatld/ijtld/2010/00000014/00000004/art00013.

9. Barbosa IR, Costa ICC. A emergência da co-infecção tuberculose - HIV no Brasil. Hygeia [Internet]. 2012 [acesso em: 26 abr. 2017];8(15):232-44. Disponível em: http://www.seer.ufu.br/index.php/hygeia/article/view/17350.

10. Centro de Vigilância Epidemiológica "Professor Alexandre Vranjac", Divisão de Tuberculose, Programa Estadual de Tuberculose. Sala de Situação de Tuberculose [Internet]. São Paulo (BR): Centro de Vigilância Epidemiológica "Professor Alexandre Vranjac" [atualizado em: 27 abr. 2017; acesso em: 27 abr. 2017]. Disponível em: http://www.tuberculose.saude.sp.gov.br/.

11. Ministério da Saúde, Departamento de Informática do SUS. Início - DATASUS [Internet]. Brasília (BR): Ministério da Saúde; c2017 [acesso em: 27 abr. 2017]. Disponível em: http://datasus.saude.gov.br/.

12. Instituto Brasileiro de Geografia e Estatística. IBGE | Projeção da população [Internet]. Rio de Janeiro (BR): Instituto Brasileiro de Geografia e Estatística; [atualizado em: 02 out. 2014; acesso em: 27 abr. 2017]. Disponível em: http://www.ibge.gov.br/apps/populacao/projecao/index.html.

13. Ruffino-Netto A. Recidiva da tuberculose. J Bras Pneumol [Internet]. 2007 [acesso em: 26 abr. 2017];33(5):xxviixxviii. Disponível em: http://dx.doi.org/10.1590/S1806-37132007000500001.

14. Belo MTCT, Luiz RR, Hanson C, Selig L, Teixeira EG, Chalfoun T, et al. Tuberculose e gênero em um município prioritário no estado do Rio de Janeiro. J Bras Pneumol [Internet]. 2010 [acesso em: 26 abr. 2017];36(5):621-5. Disponível em: http://dx.doi.org/10.1590/S1806-37132010000500015.

15. Maciel SSSV, Maciel WV, Oliveira DAL, Oliveira TF, Silva ETC, Sobral LV. Internação hospitalar por tuberculose respiratória nas gerências regionais de saúde de Pernambuco. Revista de AMRIGS [Internet]. 2011 [acesso em: 26 abr. 2017];55(3):229-33. Disponível em: http://www.amrigs.org.br/revista/55-03/0000045956-

Revista_AMRIGS_3_artigo_original_interna_hospitalar.pdf.

16. Santos MLSG, Ponce MAZ, Vendramini SHF, Villa TCS, Santos NSGM, Wysocki AD, et al. The epidemiological dimension of TB/HIV co-infection. Rev Lat Am Enfermagem [Internet]. 2009 [acesso em: 26 abr. 2017];17(5):683-8. Disponível em: http://dx.doi.org/10.1590/S0104-11692009000500014.

17. Orofino RL, Brasil PEA, Trajman A, Schmaltz CAS, Dalcolmo M, Rolla VC. Predictors of tuberculosis treatment outcomes. J Bras Pneumol [Internet]. 2012 [acesso em: 26 abr. 2017];38(1):88-97. Disponível em:

http://dx.doi.org/10.1590/S1806-37132012000100013.

18. Panjabi R, Comstock GW, Golub JE. Recurrent tuberculosis and its risk factors: adequately treated patients are still at high risk. Int J Tuberc Lung Dis [Internet]. 2007 [acesso em: 26 abr. 2017];11(8):828-37. Disponível em:

http://www.ingentaconnect.com/content/iuatld/ijtld/2007/00000011/00000008/art00002.

19. Sá LD, Barreto AJR, Nogueira JA, Cunha FTS, Palha PF, Villa TCS. The discourse of health managers on aspects related to the delay in tuberculosis diagnosis. Rev Esc Enferm USP [Internet]. 2013 [acesso em: 26 abr. 2017];47(5):1165-71. Disponível em: http://dx.doi.org/10.1590/S0080-623420130000500022. 